\title{
PESQUISAS, POLIITICAS E PRÁTICAS EDUCACIONAIS EM CURSO: CONVERSA COM ANA PAULA DUBOC E LYNN MARIO MENEZES DE SOUZA SOBRE HETEROGENEIDADE E NORMATIVIDADE
}

\section{RESEARCH, EDUCATIONAL POLICIES AND PRACTICES IN PROGRESS: CONVERSATIONS ABOUT HETEROGENEITY AND NORMATIVITY WITH ANA PAULA DUBOC AND LYNN MARIO MENEZES DE SOUZA}

\author{
Daniel Ferraz* \\ Ana Paula Duboc ${ }^{* *}$ \\ Lynn Mario Menezes de Souza***
}

\section{RESUM0}

Com a proposta de debater o tema "Entre a heterogeneidade e a normatividade: pesquisas, políticas e práticas educacionais em curso", esta entrevista, conduzida junto aos professores doutores Ana Paula Duboc e Lynn Mario Menezes de Souza, ambos da Universidade de São Paulo, nos instigou ao debate sobre o conceito de normatividade transcendental, assim como as formas pelas quais ela vem se estabelecendo como regra em discursos políticos e educacionais, ensejando, desse modo, um retrocesso baseado em políticas neoconservadoras que almejam "endireitar a sociedade, por meio de políticas afeitas à ordem, ao consenso, à homogeneidade e ao universalismo". Por outro lado, os entrevistados nos convidam a pensar que "dentro da normatividade há uma série de heterogeneidades, cada uma das quais tem a sua normatividade" e, portanto, a heterogeneidade é condição sine qua non de qualquer relação social. Esta entrevista, em forma de conversa, nos brinda com uma ampla discussão sobre linguagem, língua, políticas linguísticas e educacionais, letramentos, filosofia(s), decolonialidade, política nacional, e nos convida a uma "crítica de dentro para fora" por meio da provocação: "Qual a nossa parcela de responsabilidade como pesquisadores, como formadores de professores, como professores que estão na sala de aula, afeitos à orientação sociocultural e crítica?".

Palavras-chave: normatividade; heterogeneidade, pesquisa acadêmica; formação docente.

\footnotetext{
* Universidade de São Paulo (USP), São Paulo, SP, Brasil. danielfe@usp.br

Orcid: https://orcid.org/0000-0002-8483-2423

** Universidade de São Paulo (USP), São Paulo, SP, Brasil. anaduboc@usp.br

Orcid: https://orcid.org/0000-0002-3136-3504

*** Universidade de São Paulo (USP), São Paulo, SP, Brasil. lynnmario@gmail.com

Orcid: https://orcid.org/0000-0001-8831-7034
} 


\begin{abstract}
This interview was conducted with professors Ana Paula Duboc and Lynn Mario Menezes de Souza, both from the University of São Paulo. Based upon the theme: "Between heterogeneity and normativity: research, educational policies and practices in progress", the interview led us to debate the concept of transcendental normativity, as well as the ways in which it has been established as a rule in the political and educational discourses. These have given rise to a setback as neoconservative policies aim to "straighten society, through policies related to order, consensus, homogeneity, and universalism". On the other hand, the interviewees invite us to perceive that "within normativity there are a series of heterogeneities, each of which has its own normativity". Therefore, heterogeneity is a sine qua non condition of any social relationship. This interview/chat provides us with a broad discussion on language, educational and language policies, literacies, philosophies, decoloniality, national politics, and invites us to "critique ourselves from the inside out". It leaves us the following provocation: "What is our share of the blame as researchers, as teacher educators, as teachers who are in the classroom, who have been in favor of sociocultural and critical orientation?".
\end{abstract}

Keywords: normativity; heterogeneity; academic research; teacher education.

\title{
INTRODUÇÃO: SOBRE CRISES E MUDANÇAS
}

Sabemos que a pandemia não é cega e tem alvos privilegiados, mas mesmo assim cria-se com ela uma consciência de comunhão planetária, de algum modo democrática.

Sousa Santos, A cruel pedagogia do vírus.

Embora esta conversa com os profs. Drs. Ana Paula Duboc e Lynn Mario Menezes de Souza tenha ocorrido ao final de 2019, seria incabível ignorar o que vem acontecendo no ano de 2020 no Brasil e no mundo: a pandemia da COVID-19 e, com ela, especialmente no Brasil, um agravamento das crises econômica, política e institucional. Muitos têm afirmado que o mundo mudou. Porém, como mudou? Como mudará? Mudou mesmo? E se mudou ou não, quais aprendizados tiramos de tudo isso, deste presente, como humanidade?

As respostas de Sousa Santos (2020, p. 5) às questões supracitadas nos levam a olhar com muito cuidado para os conceitos de mudança e crise, pois "A atual pandemia não é uma situação de crise claramente contraposta a uma situação de normalidade". Para Sousa Santos, devemos entender que, quando a crise se torna permanente ela tende a explicar tudo, por exemplo, a crise financeira permanente e, com ela, o grande abismo entre os multimilionários/donos do mundo e o resto da população mundial. Estas, certamente, impõem-se de longa data e são naturalizadas pelo "capitalismo, o colonialismo e patriarcado" sendo utilizadas para explicar, por exemplo, "os cortes nas políticas sociais (saúde, educação, previdência social) ou a 
degradação dos salários" (SOUSA SANTOS, 2020, p. 5). Ainda assim, se desejamos acreditar que as crises provocadas pela pandemia da COVID-19 alteraram nossas relações sociais, não podemos nos esquecer, então, de duas crises ainda mais graves: a legitimação da "escandalosa concentração de riqueza" e o boicote de "medidas eficazes para impedir a iminente catástrofe ecológica. Assim temos vivido nos últimos quarenta anos" (SOUSA SANTOS, 2020, p. 6).

Devemos, ainda, entender de que formas as crises econômicas, políticas e institucionais alavancam crises ainda maiores, porém, propositalmente pormenorizadas por aqueles que detêm o "tempo político e mediático" (SOUSA SANTOS, 2020, p. 22); tais crises condicionam os modos como a sociedade contemporânea se percebe. "Esse modo pode ser-nos fatal. As crises graves e agudas, cuja letalidade é muito significativa e muito rápida, mobilizam as mídias e os poderes políticos, e levam a que sejam tomadas medidas que, no melhor dos casos, resolvem as consequências da crise, mas não afetam as suas causas" (SOUSA SANTOS, 2020, p. 22).

Mas como essas questões se relacionam com os entrevistados e suas perspectivas epistemológicas e ontológicas? De que maneiras as provocações de Sousa Santos lhes/nos ajudam a entender o que estamos passando no Brasil, em termos políticos e educacionais? Bem, a profa. Dra. Ana Paula Duboc é, sem dúvida, uma pesquisadora respeitada e de grande renome nas áreas de Formação de professores de línguas, Linguística Aplicada Crítica (LAC) e Educação no Brasil. É docente na Faculdade de Educação da Universidade de São Paulo (FEUSP), onde atua na graduação e na pós-graduação. Coordena a Área de Linguagem do Departamento de Metodologia do Ensino e Educação Comparada (EDM) e o CEPEL - Centro de Estudos e Pesquisas no Estudo de Línguas da FEUSP. Na esfera internacional, desenvolve o projeto de pesquisa multilateral Literacy policies and practices: a comparative study between Brazil, South Africa and the United States, realizado em parceria com a University of Wisconsin-Madison, Estados Unidos e a University of Cape Town, África do Sul. Em sua obra, Duboc vem discutindo, de forma extremamente multifacetada, temas como: ensino e aprendizagem de línguas estrangeiras, avaliação de línguas estrangeiras, letramentos, estudos decoloniais e formação de professores de línguas.

Nosso segundo entrevistado, o professor Dr. Lynn Mario Menezes de Souza, é um dos grandes filósofos decoloniais brasileiros. Professor da Universidade de São Paulo, coordena, junto à Profa. Walkyria Monte Mór, o Projeto Nacional de Letramentos: Linguagem, Cultura, Educação e Tecnologia (USP, 2015-2021). No cenário internacional, vem desenvolvendo pesquisas e parcerias com diversas 
instituições. É pesquisador do projeto internacional Pensando Goa, colaborador do projeto Reimagining Multilingualism da University of the Western Cape, África do Sul, e colaborador do projeto Gesturing Towards Decolonial Futures, da University of British Columbia, Canadá. Anualmente, Menezes de Souza é professor visitante na University of Western Ontario, UWO, Canadá, University of Oulu, OULU, Finlândia e Università degli Studi di Padova, UNIPD, Itália e Universidade de Oslo, Noruega, para citar algumas. Em sua obra, afirma sua recusa a afiliações teóricas radicais e, ao mesmo tempo, derrideanamente falando, reafirma suas afiliações contextuais às mesmas, sempre nos lembrando que devemos não somente perceber e assumir os nossos locais de enunciação, mas sempre, nesse processo, ler-nos ao mesmo tempo em que lemos o outro (essa é a sua releitura de Freire).

Portanto, esta conversa, realizada no $1^{\circ}$ Ciclo de Palestras do GEELLE Grupo de Estudos sobre Educação Linguística em Línguas Estrangeiras (FFLCHUSP) em novembro de 2019 nos brinda com o debate sobre normatividade e heterogeneidade colocadas no contexto da educação linguística em línguas estrangeiras no Brasil. Como se tratou de uma entrevista em formato de bate-papo, decidi manter a informalidade da conversa com a esperança que seja também um bate-papo com você, leitora. Assim, agradeço aos professores Ana Paula e Lynn Mario pela oportunidade do debate, aprendizagem e expansão de perspectivas. Outrossim, agradeço aos participantes do GEELLE, pela participação e um agradecimento especial à Gabriela Tomizuka, nossa monitora do GEELLE e do Projeto Nacional. Espero que o leitor se encante, como eu, com as discussões aqui ensejadas.

Prof. Dr. Daniel Ferraz

\section{ENTREVISTA}

Daniel Ferraz (DF): Boa tarde Ana e Lynn. Primeiramente muito obrigado pelo aceite. Os temas propostos são instigantes e tenho certeza que todos terão muito a aprender. Vamos começar com a profa. Dra. Ana Paula. Ana, pensando no título da conversa, Entre a heterogeneidade e a normatividade, como você pensa esses conceitos, extremamente filosóficos, em tempos contemporâneos?

Ana Paula Duboc (APD): O título proposto desse debate é "Entre a heterogeneidade e a normatividade: pesquisas, políticas e práticas educacionais em curso" e eu fiquei pensando como eu começaria a minha fala e talvez problematizar o próprio título, porque quando a gente pensa na preposição "entre" não sei em que medida ela pressupõe uma lógica binária pautada no "ou isso ou aquilo" quando, na verdade, não 
seria saudável já pensar na coexistência da heterogeneidade e da homogeneidade ou aquilo que a gente tem falado aqui, a normatividade? $\mathrm{E}$, ao mesmo tempo, pensarmos em outros termos. Então, no lugar de "entre" uma e outra, eu vou falar na heterogeneidade " $e$ " na normatividade. Como que a gente resolve alguns dilemas estando inscritos o tempo todo dentro de ambas lógicas, que sempre existiram, que sempre estiveram presentes?

Goodwin (2010) diz em um determinado texto dela que a diversidade, "is out there doing its job"; algumas diferenças se tornaram mais visíveis, mas o fato é que elas sempre existiram e algo que sempre aprendi nas suas palestras, Lynn, é uma frase sua que eu sempre uso com os alunos da graduação que é aquela coisa de que "há heterogeneidade na homogeneidade". Aquilo que a gente pensa ser homogêneo sempre carrega a heterogeneidade. E aí eu vou tentar dividir um pouco a minha fala pensando em como em determinados tempos históricos uma e outra lógica foram colocadas mais à tona nos holofotes. Então, eu vou situar a minha fala um pouco resgatando o colonialismo, passeando pelas contribuições da teoria pós-colonial, chegando nesses tempos neocoloniais que estamos vivendo agora, não só no Brasil, mas em outros países do mundo; para, quem sabe, pensar na decolonialidade como uma alternativa interessante, nessa coexistência de forças que supostamente são bastante conflitantes.

Resgatando historicamente, a lógica do "one language, one nation, one culture", predominante até a primeira metade do século XX serviu para a criação do Estadonação no paradigma moderno como forma de alinhavar o todo de uma nação. Nesse momento, nós tivemos os holofotes voltados para a homogeneidade, para os universalismos, para a normatividade. Foi então a invenção da lógica do mono, a orientação monolíngue, monocultural, a ideia de língua nacional, identidade nacional. O colonialismo que sustentou a existência de muitos Estados-nação reproduziu essa lógica nas colônias, cujas heterogeneidades foram normatizadas por meio de violentos processos de assimilação, extermínio ou expulsão. No que diz respeito ao conceito de língua, como é que a Linguística, como ciência emergente ainda na primeira metade do século XX, respondeu a esse movimento? Partindo de uma orientação estruturalista, saussuriana depois chomskyana; a preocupação esteve muito voltada para a descrição do fenômeno linguístico. Mas sempre estiveram os linguistas inscritos em um lócus de privilégio, falando de um gabinete de uma língua ideal, de um falante ideal, uma linguística de certa forma laboratorial que tem um falante ideal, então era relativamente fácil descrever os fenômenos da língua na medida em que as complexidades, as heteroglossias, as heterogeneidades marcantes na língua pulsante, dinâmica, na língua entendida como prática social 
foram negligenciadas deliberadamente num dado momento histórico. No campo das línguas estrangeiras, especificamente, para muitos de nós que lidamos com LE, a gente sempre teve essa ideia do falante estrangeiro, do falante não-nativo sempre inscrito em um lócus de deficiência, em um lócus de lacuna na medida em que muitos de nós transitamos por vocábulos de teorias de aquisição de línguas como "língua-alvo", "aquisição de língua", "subusuário", "interlíngua", "proficiência" como se fosse possível adquirir a língua em sua totalidade.

Aquela ideia de "interlíngua" muito debatida pelas teorias de aquisição de línguas estrangeiras, o subusuário. Imagine pensar num falante como subusuário de uma língua estrangeira, sempre tendo o falante nativo como aquele que deve ser imitado, pautado muito na lógica da precisão, da pureza e da imitação. Quer dizer, o ensino da língua estrangeira ou de primeira língua sempre partiu dessa normatização em que primeiro se parte da regra da língua-padrão para depois vir com a língua em uso como mero fim ilustrativo para exemplificar ou corroborar aquilo que na sala de aula a gente traz como as regras, as normas de uma língua. Então, o falante nativo - e cumpre esclarecer, não qualquer nativo, mas o que tem o selo norteamericano ou britânico - é a norma, é aquele que deve ser imitado. Essa visão altamente normatizada de língua foi corroborada nos primeiros estudos linguísticos altamente descritivos, sob uma visão estruturalista.

Na segunda metade do século XX, a chamada virada linguística abalou um pouco as teorias de aquisição de línguas das épocas, com o estabelecimento de um diálogo entre a Linguística e outras áreas do conhecimento como a Sociologia, a Antropologia e a Teoria Crítica. A publicação do artigo de Firth e Wagner (1997) trata disso, acirrando o debate no campo da linguagem, que, a meu ver, marcam os primeiros passos da Linguística Aplicada. Depois tivemos a Linguística Aplicada Crítica, em que começou-se, então, a denunciar o mito do monolinguismo e a falácia das chamadas named languages, ao mesmo tempo em que passou-se a considerar a relação intrínseca entre linguagem e questões culturais, étnico-raciais, identitárias, ideológicas. Então, a invenção do monolinguismo nos idos do surgimento dos Estados-nação, como garantia do alinhavo necessário para a criação desses Estadosnação, começou a ser questionada, problematizada, legitimando-se, então, a prática situada e contextualizada da língua. A língua como prática social e a legitimação dos usos mestiços, mixados, hibridizados da linguagem. No início, reconhecese que os primórdios da Sociolinguística ainda falavam muito em code-switching e aí a gente pode estabelecer a crítica a um certo essencialismo presente nessa primeira Sociolinguística. De todo modo, houve aí na segunda metade do século $\mathrm{XX}$ a contribuição de outras disciplinas, outro olhar que já começou a ser mais 
interdisciplinar na medida em que a gente começou a legitimar os usos sociais e culturais da língua. Então, conforme sinaliza Blommaert (DUBOC; FORTES, 2019), se o desvio antigamente era exceção, era problema, e era erro, o desvio então passa a ser norma, porque é o que está posto nos usos reais, situados e contextualizados da língua.

Se considerarmos as políticas educacionais brasileiras, a gente percebe visivelmente essa visão sociocultural e discursiva de linguagem nos muitos documentos curriculares que regulam a educação básica, seja para a língua portuguesa, ou para línguas estrangeiras, sobretudo sob influência da teoria bakhtiniana de gêneros, como é o caso das muitas propostas curriculares para ensino de língua portuguesa. Quando a gente olha para esses desenhos curriculares brasileiros, ninguém mais ousa voltar àquela linguística convencional, ao menos teórica e discursivamente; ninguém ousa afirmar que língua é código, língua é sistema, língua é estrutura. Não, isso os nossos currículos, parece que já "resolveram". Na segunda metade do século XX, toda a contribuição das teorias pós-modernas, sobretudo as pós-estruturalistas, os estudos culturais, os estudos pós-coloniais acabam por corroborar o valor dessa visão sociocultural e ideológica de língua e de ensino de línguas ao colocar em cheque a hegemonia de determinados saberes trazendo à tona a necessidade de legitimar saberes que até então estiveram historicamente apagados e subalternizados. Então, aqui, nesse momento, estamos falando mais da língua em uso, agora, como ponto de partida, em que a regra ou a norma passa a ser ponto de chegada, teoricamente, e isso arremete à ideia de falácia da regra em Bourdieu (1977) e da necessidade de questionarmos o que vem primeiro, a língua ou a regra da língua. É a língua que precede a própria regra. No entanto, a escola tradicionalmente vem colocando a norma, a regra, em primeiro lugar tornando o ensino absolutamente abstrato, sobretudo para aquelas crianças e alunos cujas práticas de letramento não escolares não dialogam com os letramentos escolares.

Bem, e hoje como é que estamos? Em que pé estamos em pleno século XXI, 2019? Já são quase 40 anos de uma orientação sociocultural discursiva, já são quase 40 anos de pesquisas sobre educação linguística, sobre linguagem que valorizam e legitimam os usos sociais da língua, a língua em seu contexto de uso ; já faz 40 anos que temos legitimado em políticas, em pesquisas, e também em práticas educacionais, os usos heterogêneos desta língua.

O ponto que eu quero trazer aqui é justamente problematizar o lugar da normatividade, já que hoje temos um retrocesso em políticas neoconservadoras querendo endireitar e consertar a sociedade por meio de políticas afeitas à ordem, ao consenso, à homogeneidade, ao universalismo, à normatividade. Estou dizendo 
em termos tanto de movimentos sociais, quanto de políticas, decretos, e leis que de fato foram revogadas ora mesmo elaboradas pelo atual governo. Estou falando do Movimento Escola Sem Partido, estou falando de Base Nacional Comum Curricular (BNCC), estou falando da nova Política Nacional da Alfabetização (PNA), do Programa Nacional das Escolas Cívico-Militares, o movimento Pro-Homeschooling e por aí vai. São políticas, são movimentos que tendem restabelecer ou, no caso, "endireitar a sociedade", por meio do apagamento da diferença e do dissenso e a valorização da normatividade, ou, de um determinado tipo de normatividade. De novo, tem-se a velha polarização, ou aquilo que o Lynn Mario falou num debate recente que tivemos aqui, da separabilidade: o fenômeno versus o seu contexto, a parte versus o todo, o observador versus o observado, rumo ao suposto progresso pautado na ciência de verdade, na ciência que é mais objetiva, que não olha para esses usos heterogêneos de língua, não olha para essa heterogeneidade toda que há boas décadas temos legitimado.

Um ponto que eu queria só esmiuçar rapidamente é tratar um pouco dessa questão, porque muitos de nós estamos lidando com pesquisas sobre língua, linguagem e letramentos, e quando a gente olha para a PNA, em particular, já houve um tempo num passado recente, uma tentativa de consertar, de certa forma, certa má compreensão quanto ao socioconstrutivismo. A Magda Soares (2004), por exemplo, publicou no início dos anos 2000 um artigo em que ela afirma a necessidade de reinventar a alfabetização, reinventar o letramento. $\mathrm{O}$ argumento dela era assim: olha, é preciso a gente voltar a falar de certas especificidades, de certas dimensões da língua, que foram muito criticadas por uma orientação sociocultural, mas que precisamos, sim, voltar a falar delas, na medida em que temos quase 12 milhões de brasileiros analfabetos. Belintane (2017) - colega meu da FEUSP, da Área de Linguagem - também bota o dedo na ferida ao expor sua dura crítica aos socioconstrutivistas que, erroneamente, teriam investido muito na ideia de que "cada criança tem seu tempo", ou mesmo nas metodologias ditas mais ideológicas, as quais, para ele, acabaram num reducionismo metonímico que elege uma dimensão do letramento e tangencia outras. Ou o próprio Saviani (2013), nos anos 80, em um texto polêmico em que ele denunciou uma certa falácia da Escola Nova quando se colocou como modelo afeito à democracia quando, na verdade, certas estratégias do movimento escolanovista como a resolução de problemas, a centralidade do aluno, paradoxalmente não equacionaram muito bem a heterogeneidade da sala de aula. Muitos outros textos contribuem para a gente pensar essa complexa relação entre heterogeneidade e normatividade, uma discussão que perpassa a questão da inclusão e da democracia, Soares e Belintane, cada qual a seu modo e partindo de argumentos 
distintos, tentaram e tentam falar dessas questões, sem, claro, defender a língua como código, a leitura como decodificação, o ensino de língua pautado num rotelearning artificial e abstrato. Atualmente, como pesquisadora da área da linguagem e dos letramentos, tenho pensado cada vez mais na necessidade de problematizarmos essas coisas, aproximando-nos desse debate já em curso por colegas mais voltados ao ensino da língua portuguesa, compreendendo os pontos de interseção e aqueles que destoam, porque tenho me questionado, mais recentemente, em que medida a gente também não incorre num risco ou armadilha de falarmos entre iguais e de polarizar a heterogeneidade de um lado, a normatividade de outro, quando, na verdade, é preciso equacionar essa balança de modo a fazermos jus a uma educação que seja inclusiva e democrática. Não dá para estabelecer a priori uma proposta pedagógica, é isso. A prática social deveria ser o ponto de partida, com a definição e o estabelecimento de práticas pedagógicas a posteriori. Qualquer estabelecimento de uma prática pedagógica a priori é fadada ao fracasso, na medida em que você precisa viver, conhecer esse aluno, se situar historicamente, partir daquela prática social para, de fato, verificar qual é a dimensão da língua, qual é a dimensão dessa educação linguística que será mais inclusiva para aquela criança ali cujos letramentos não escolares, muitas vezes, estão bastante distantes dos letramentos escolares.

Estou dizendo isso porque a orientação sociocultural e crítica que estamos tanto defendendo e debatendo tem também as suas falhas, e eu acho que é o momento agora, nesse neocolonialismo que a gente vive de, talvez, repensar o lugar da normatividade e que normatividade é essa, tentando um pouco evitar essa armadilha da separabilidade. Então, proponho partilhar alguns questionamentos para ouvirmos, primeiramente, o Lynn e depois abrirmos para um debate com todos: Lynn, haveria um meio-termo quando falamos de heterogeneidade e normatividade? Porque parece que quando falamos de "normatividade" há uma certa alergia ao termo, como já dito por Blommaert (DUBOC; FORTES, 2019). Parece que a gente se tornou alérgico a algumas palavras quando a gente adota uma dada visão de língua, de sujeito, de conhecimento, de escola, de pedagogia, quando, na verdade, a gente precisa talvez destituir o fardo semântico desses vocábulos para talvez pensar em outros termos; mudar os termos da conversa, ressignificar sob outra lógica. Então, haveria um meio-termo quando falamos de heterogeneidade e normatividade? Houve, na sua opinião, uma má compreensão dessa orientação mais socioconstrutivista, dessa orientação sociocultural e crítica, o que, inclusive, gerou fortes acusações sob um suposto vale-tudo? Essa é uma crítica que os pósmodernos ouviram muito "ah, agora vale tudo. Tudo pode". Qual a nossa parcela de responsabilidade como pesquisadores, como formadores de professores, como 
professores que estão na sala de aula, afeitos à orientação sociocultural e crítica? Estou propondo uma crítica de dentro para fora. Não é criticar o outro lado da polarização, é criticar este lado aqui, este lócus aqui, partindo, aliás, dessa premissa decolonial, de não nos colocarmos no ponto zero do saber, não nos colocarmos nessa verdade forte que de certa forma às vezes ecoa certa arrogância. É preciso reconhecer nossas próprias ignorâncias, acertos e desacertos. Como é que a gente legitima esse pluralismo epistêmico dentre os próprios pares que estão inscritos em uma visão sociocultural e crítica? Eu não sei se estou clara na minha proposta, mas o fato é que a gente coloca que a orientação sociocultural é inclusiva, é democrática, mas o fato é a gente precisa discutir outros termos; a gente precisa mudar os termos dessa conversa, compreender, então, onde ela falhou - seria fruto de um misunderstanding? Ou fruto de más condições de implementação dessas práticas nos sistemas escolares? - nesse exercício de mea culpa e de ler nos lendo (Menezes de Souza, 2011), reconhecendo como é que a gente vislumbra caminhos outros. Os estudos sobre decolonialidade podem ser uma alternativa interessante, mas isso certamente o Lynn Mario tem muito a dizer.

Lynn Mario Menezes de Souza (LMMS): Essas questões de heterogeneidade e normatividade são questões que me acompanham há 40 anos, mas eu vou começar pelo comentário da Ana sobre a alergia a isso ou aquilo; alergia, como sabemos, pode matar. Então, vamos esclarecer isso primeiro. Eu vou começar pela questão da normatividade, apesar de eu sempre preferir começar com considerações sobre heterogeneidade. Mas, para mim, há dois tipos de normatividade: tem uma normatividade implícita, imanente, não refletida, que faz com que a gente fale igual aos nossos companheiros, aos nossos familiares, aos membros da mesma comunidade. Nesse contexto, ninguém vai dizer para nós "fala assim e não assado, é assim que se fala, isso é correto, isso não é correto". É uma normatividade que a gente aprende inconscientemente que, aparentemente, é uma normatividade não regrada, mas é, sim, regrada, portanto, é normatizada. A gente fala igual à comunidade em volta, aos familiares em volta, mas é uma normatividade não reconhecida. Isso gera a impressão, por exemplo, para professores de língua materna que eles gostam de pensar que, se você não souber usar a gramática, você fala de uma forma agramatical. Isso não é verdade: você está seguindo uma norma, mas é uma outra norma.

Agora, o que seria a gramática? Seria esse outro tipo de norma, que é uma normatividade refletida, artificial, produzida, consciente e, eu diria, até transcendental, no sentido de contrastá-la com uma normatividade imanente que vem de dentro para fora. Uma normatividade transcendental no sentido de que vem de fora. É uma normatividade que é produzida através de uma reflexão sobre 
como é que a linguagem funciona. Então nós temos que parar e interromper o fluxo normal da linguagem para refletir sobre a linguagem e identificar aí determinadas regras recorrentes e porque acabamos confundindo essas regras com uma certa normatividade. Mas isso não é de graça. Para podermos confundir essa natureza regrada da linguagem com a normatividade, nós temos que partir de um lugar de poder. Eu preciso estar em um lugar em que eu posso dizer para o outro "é assim e não é assado, é assim que se deve falar e não assado, é assim que se deve escrever e não assado". Então, duas coisas que criam, para mim, esse conceito de normatividade que eu estou chamando de normatividade transcendental: primeiro, uma reflexão que significa uma abstração, você tira do fluxo natural da linguagem, você a abstrai do contexto, essa é uma normatividade sempre abstrata, descontextualizada e refletindo sobre essa linguagem o uso, o linguajar, vamos dizer, você identifica determinadas regras.

Saussure percebeu que a prática da linguagem é muito pouco regrada, mas a abstração, o pensamento abstrato da linguagem, é um momento onde se pode chegar a uma definição e identificação de regras. Então, as regras que nós costumamos associar com a normatividade são sempre produtos dessa normatividade abstrata, artificial, transcendental, e de um lugar de poder. Uma normatividade que, daí, vai ser imposta, porque por ter sido abstraída do fluxo do linguajar, por ter adquirido um tempo de reflexão, esses aspectos parecem que autorizam, legitimam o poder de quem vai falar em um lugar, autorizado por uma certa normatividade. E essa normatividade é aquela que a gente encontra nas propostas gramaticais de língua materna, de língua estrangeira etc.

Essa normatividade inverte a posição da heterogeneidade, pois ao invés de perceber que a heterogeneidade vem primeiro, eles invertem o processo e acham que a normatividade, a singularidade que vem primeiro, depois a heterogeneidade: é uma singularidade + outra singularidade + outra singularidade. Heterogeneidade não é $1+1+1$, não é uma composição, uma justaposição de unidades separáveis e independentes. Heterogeneidade é essa massa amorfa de linguajares, não de línguas, de formas diferentes, onde as pessoas vão falar de acordo com seu gênero, sua faixa etária ou classe social; a fala vai variar se está ocorrendo verbalmente ou oralmente ou por escrito; todas essas variações contribuem para essa natureza amorfa que, para mim, é a heterogeneidade. Mas, para quem parte desse conceito de normatividade abstrata, transcendental, - agora vocês podem entender porque eu escolhi a palavra transcendental, não só porque significa de fora para dentro, mas também como coisas; propostas transcendentais vêm com "eu sou autorizado por um poder transcendental" - então vem como propostas divinas, digamos. Quem 
fala da normatividade, dessa visão transcendental, acha que a heterogeneidade é uma série de normatividades. Não é. A heterogeneidade, eu diria que é, digamos, o ponto zero. O estágio natural da linguagem, que inclui a tossida, o espirro, tudo aquilo que o nosso aparelho fônico é capaz de produzir, isso seria a heterogeneidade da fala de uma única pessoa; agora, juntem isso com outras. E, nesse sentido, todos nós somos heterogêneos e multilíngues. Mas agora vou radicalizar nesse conceito: mesmo sendo monolíngues, por que falamos a língua da nossa faixa etária, a língua do nosso gênero, a língua da nossa região de origem geográfica, e falamos a língua também da nossa nação?

Não é para dizer que agora que temos a heterogeneidade, pois acabou a normatividade. Nós podemos dizer que dentro da normatividade há uma série de heterogeneidades, cada uma das quais tem a sua normatividade. Então, a gente precisa recuperar aquela ideia de normatividade implícita que eu falei antes, não a transcendental. Uma ação - para não dizer "forma" e para não separar pensar de agir - uma ação linguística é sempre uma ação convencionada.

Toda a ação convencionada segue uma regra que não fomos nós que falamos, não fomos nós que inventamos. Como disse Freire (2014), antes de eu ser o eu de mim mesmo, eu fui você de um outro. Ou seja, eu aprendi como dizer e como significar através de pessoas que me antecederam. Então, não fui eu que inventei a linguagem. A heterogeneidade no sentido de linguagem do ethos do outro já está na origem da linguagem. Eu aprendo a linguagem de um outro, tanto que a diferença está na origem do outro. A linguagem não é algo que vem do ego e é só por aí. Então, eu estou problematizando esse desejo que nós encontramos de polarizar ou heterogeneidade ou não heterogeneidade, ou normatividade ou não normatividade.

Outro aspecto importante a considerar: aqueles que gostam de falar em normatividade não nos deixam esquecer que vivemos, atualmente, em um momento neoconservador, que impõe uma normatividade, esquecendo que há outras. Ok, eles defendem a normatividade, não há como criticar normatividade, porque qualquer coisa que a gente faz dentro de um ambiente social é normatizado, as normas mudam justamente porque temos uma pluralidade de normas que coexistem e esse contato entre normas diferentes geram outras normas, então normatividade não significa singularidade. Essa confusão dessa onda neoconservadora que acha que há, sim, um jeito de agir, de pensar, de ser. Normatividade existe em todas as comunidades, agora o que eles entendem como normatividade é essa normatividade transcendental e, no caso deles, é até uma normatividade divina. Vocês podem pensar no momento em que nós estamos; esse momento em que nós estamos vai dizer que "ah, vocês são gente da academia, fazem balbúrdia, porque vocês não obedecem 
normatividade nenhuma". O que acontece nessa situação é uma incapacidade de imaginar outras formas de normatividade. Uma conclusão é uma polarização de achar que "se você não segue a minha norma, você não tem norma nenhuma". Isso é um processo perigoso e nos leva a um processo violento de exclusão: "se você não é igual a mim, você não é ninguém". Então é isso que querem nos dizer, que nós não somos ninguém, portanto não valorizam aquilo que a gente pensa, aquilo que a gente faz, aquilo que a gente produz, porque nós não somos iguais a eles e eles são detentores da normatividade, aí tem essa volta para essa conexão entre normatividade e heterogeneidade.

Uma das coisas que Bakhtin assinala ao tratar do conceito de heteroglossia, é que o estado natural das línguas é ser plural, é ser heteroglóssico; e quando surge a homogeneidade é sempre um produto de um pulso de poder. Um desses elementos da heterogeneidade quer se impor sobre os outros, então esse elemento vai dizer que é o único elemento que vale, então vai querer invisibilizar a pluralidade dos outros.

É assim que surgem as línguas nacionais, assim que surgem as nações. Se olharmos o caso da Inglaterra, por exemplo, no século XVIII, em uma época em que $95 \%$ da população britânica era analfabeta, a elite inglesa queria, por medo da capacidade de agressão de violências das hordas - era assim que eles olhavam para o povo, as hordas -controlar essa ameaça constante, na perspectiva deles, das hordas, e precisavam impor uma língua. Óbvio que essas hordas falavam suas línguas, mas não eram reconhecidas como sendo inglês. Agora, a língua da elite, a língua do John Locke, por exemplo, era a língua - essa visão é assim que funciona.

No caso de Locke, a forma que se chama de "inglês" surgiu como a forma da elite, da alta burguesia inglesa, virou a língua da nação e para pacificar a nação era essa a língua que passou a ser a língua da instituição escolar. Então, inventou-se entre a heterogeneidade de ingleses ou de formas da língua inglesa que existiam na época, escolhendo-se uma e impondo-se essa LI como a língua, sequestrando o nome "inglês" e invisibilizando as outras. Essa história segue em todas as outras nações.

As políticas linguísticas tentam sempre controlar a heterogeneidade. Bom, algumas políticas não, mas em momentos mais conservadores nós vamos ver a heterogeneidade tachada como negativa e, em momentos mais liberais, o contrário acontece. Agora, o erro é sempre quando a gente liga, conecta, equivale a heterogeneidade com a não-normatividade. Não é verdade. Dentro da heterogeneidade, há uma pluralidade normativa. Se não houver normatividade, não 
é uma prática linguajar, porque toda prática linguajar é uma prática social, portanto, sujeita a convenções. E convenções, o que são? São normas.

DF: Ana e Lynn, como podemos conectar essas visões de normatividade e heterogeneidade com a educação, com a escola? E, em especial, o que os movimentos dos letramentos teriam a dizer a respeito?

APD: Lynn, você falou, em algum momento, que a heterogeneidade vem primeiro, ela vem sempre primeiro, mas eu tenho pensado que ela vem primeiro, mas não vem sozinha, na medida em que há normatividades atravessando essa heterogeneidade o tempo todo. Mas o ponto que tem me incomodado e que, talvez agora a gente precise falar disso de uma forma mais explícita e veemente - e é isso que eu tentei trazer em minha fala inicial - é que me parece que nós corremos o risco de colocar a heterogeneidade como algo absolutamente prioritário e importante e deixamos de tratar de normatividades. Eu tenho a impressão de que alguns programas de letramento, práticas de letramento que ocorrem na sala de aula de certa forma compreenderam mal essa grande ênfase que se deu aos usos sociais da língua, colocando a devida valorização aos usos heterogêneos da língua quando, na verdade, já que há normatividades nessa heterogeneidade, há uma metacognição que é importante, uma metalinguagem que é importante, uma sistematização que é importante, mas não aquela sistematização que vê língua como código, como sistema; uma sistematização mais voltado a um exercício de "falar sobre a língua" de maneira situada, contextualizada. Para nós, pesquisadores dessa área, me parece que a decolonialidade enseja uma nova postura que ajudaria a mudar os termos da conversa na medida em que ela desvela a colonialidade do saber e a colonialidade do poder por trás de certas normatividades que estão postas como as legítimas, enquanto outras sequer são pensadas pelo próprio professor como uma norma.

Ou seja, a criança vem e diz de certo modo, pautado ali numa dada norma que a depender do seu contexto social, do seu lócus, não é tida como norma e não passa pelos crivos da escola. Até que ponto, fico pensando, nós não travamos esse diálogo de modo a, enfim, evitar que não se fale mais de norma? Como, então, podemos voltar a falar de normas, não a do tipo transcendental - como você abordou - mas a do tipo imanente, que pudesse servir, no momento certo da aula, como um combustível para uma metarreflexão situada, contextualizada sobre a língua? Quando digo que há uma certa alergia a certas ideias, eu estou dizendo sobre a alergia a certos vocábulos que a gente vê do lado de lá sendo trazidos como a solução, a salvação enquanto outros são postos como problemáticos e proibidos a priori. Eu acho que a gente precisa travar essa conversa com o professor e entre 
nós mesmos que lidamos com pesquisas; e, já que temos falado tanto em letramento crítico, me parece que a escola é o lugar em que a gente pode então desenvolver LC como exercício que ajuda a compreender e traçar a genealogia das coisas, do ranço colonialista nas questões linguísticas, por exemplo, para então pensarmos em outras alternativas, outros meios, outros caminhos.

Dos entendimentos de crítica que a gente vem travando, já problematizamos bastante a ideia liberal-humanista de crítica como mero discernimento; também compreendemos certas limitações na ideia de crítica como desvelamento de interesses e poderes por trás do texto; e chegamos, mais recentemente, numa compreensão de crítica como exercício de ler-se lendo (MENEZES de SOUZA, 2011). Parece-me que esse outro momento de Letramento Crítico como ler-se lendo somado ao olhar decolonial, constitui uma alternativa que imprime outra força para esse exercício crítico que se pretende quando a gente fala de Letramento Crítico, entendido como aquela ideia do ler-se lendo sob as lentes da decolonialidade para entender como a gente vai sair dessa polarização. Como a gente trava um diálogo com o outro cujas visões de mundo e perspectivas são absolutamente distantes? Me parece que o primeiro passo é travar um diálogo entre pares. Esse exercício de ler-se lendo sobre uma perspectiva decolonial entre pares para então pensar modos a fazer valer essas normatividades que não são tidas como norma.

LMMS: Bom, antes de responder essa pergunta queria voltar um pouco para como a não-normatividade, ou como uma suposta não-normatividade, acaba virando normatividade. Nós passamos por isso em várias propostas educativas nos últimos dez anos. Eu estou pensando no fenômeno de ensinar o gênero textual que virou modelo. Isso era uma reação contra o foco na gramática, então vamos procurar uma coisa que vem da prática textual, e aí surgiu o gênero textual que, a meu ver, cita Bakhtin como dono da ideia de uma forma muito desmerecida. Bakhtin não normatizava o conceito de gênero textual e o que nós vemos nessas propostas curriculares de gênero textual: é "assim que se escreve um gênero, vamos dizer, um texto publicitário, um texto literário", essas são as regras internas desse gênero, então o aluno é levado a reproduzir essas regras internas e é levado a entender que esse tipo de gênero textual é algo fixo, normatizado e seguirá para todo o sempre de forma transcendental essas regras. Ou seja, normatizou um conceito que Bakhtin aponta simplesmente a ideia de - lembra que eu falei que há dois tipos de normatividade? - isso vem das minhas leituras de Bakhtin, apesar de Bakhtin não falar disso da mesma forma. Mas quando o Bakhtin fala de gêneros textuais, ele quer mostrar que há outras formas que não são só de Linguística, há outras 
formas de organização de linguagem que vêm das práticas de linguagem, mas não são normatizadas.

Se eu olhar em qualquer momento da história, se eu olhar como é que se escreve, por exemplo, podemos olhar, hoje em dia, como é que as pessoas mandam mensagens de texto, vamos tentar identificar a regra imanente, implícita nesse tipo de mensagem, mas daí para dizer que essa é a gramática dessa mensagem e agora escrever mensagem de texto você tem que seguir essa norma, o que você está fazendo? Congelando o fluxo natural, a possibilidade de mudança desse tipo de linguagem. Então, o que Bakhtin estava apontando era, na minha leitura, essa ideia de que nas práticas textuais não são aleatórias, simplesmente porque não estão seguindo as formas gramaticais; estão seguindo o tipo de normatividade que vem da prática, mas aquela normatividade não pode ser abstraída, reproduzida, institucionalizada, porque vai tornar aquela normatividade que está imanentemente na prática, vai tornar aquilo transcendental e imposta de fora e vai congelar o fluxo natural da linguagem. Então, a normatividade aparentemente afastada nas propostas de ensino de gêneros textuais, nas propostas curriculares, por exemplo, acabou caindo em outro tipo de normatividade.

Agora, para entender a questão: como é que está a nossa leitura crítica hoje em dia com a perspectiva decolonial? Esta pressupõe que a maneira em que aprendemos a ver o mundo ou organizarmos o mundo não é uma maneira natural - apesar de ser uma maneira naturalizada -; é uma maneira aprendida e aprendida dos outros. Em nosso caso, aprendida daquelas culturas que nos colonizaram e nós acabamos reproduzindo essas maneiras de ver o mundo, e essas maneiras de ver o mundo têm origem em uma coisa bem forte que nos afeta até hoje, que é a modernidade, a qual vem sem qualificador, "Modernidade", como se fosse uma única e sempre para todos.

Quando nós falamos da modernidade, nós estamos falando da modernidade europeia que nós herdamos através da colonização. A colonização acabou, mas os efeitos continuam e os seus efeitos no seu sentido que os nossos modelos acadêmicos, o modelo da universidade que a gente tem ainda é um modelo deles, coloniali $_{\text {; }}$ ainda reproduzimos os valores da modernidade que vieram da Europa, do Iluminismo, que valorizaram duas coisas: o ser humano como sendo superior a outras formas de vida. E por quê? Porque ele tinha a faculdade da razão. Então, essas duas coisas, a racionalidade e o humanismo, produziram a ciência, uma ciência que se pauta na abstração. O que significa abstrair? Extirpar, remover, se lembrarmos de onde vem essa palavra. Remover o quê? Por que a gente gosta muito de teorias na ciência? A objetividade é sempre uma abstração. Ciência é uma coisa abstrata. 
Abstraímos por quê? Para melhor estudarmos fenômenos da natureza precisamos removê-lo do seu contexto de ocorrência original, então, tiramos esse fenômeno para o laboratório. Nesse laboratório, por que no laboratório? Por que a nossa racionalidade é uma racionalidade que segue uma lógica formal da dedução, então nós precisamos analisar, ou seja, o que significa analisar? Quebrar em partes, dividir em partes, e depois precisamos sintetizar, tentar colocar de novo as partes para ter a certeza se entendemos a construção do elemento. Então, quebramos, analisamos, tiramos partes, depois recolocamos e aí ficamos satisfeitos com essa metodologia científica, mas o que deixamos de fazer nessa metodologia científica, que se pautou na separabilidade, ou seja, na abstração inteira? O resultado é abstraído, removido, o fenômeno da natureza de seu contexto original de ocorrência. Quando a gente recompõe as partes do objeto analisado, o todo que a gente enxerga não é o todo do fenômeno original, pois o que está faltando? O contexto de ocorrência original. Então, a ciência produziu todo o nosso conhecimento sem levar em conta, isolando os fenômenos e esquecendo contexto original, que é o quê? Da natureza do nosso planeta.

Então, nós temos a ciência somada ao capitalismo, o lucro, o processo industrial, o consumo, e acabamos na situação que temos hoje. Por exemplo, nós, acadêmicos e cientistas, não pensamos nas sequências dos nossos atos. $\mathrm{O}$ que nós pensamos, não agimos. Mas pensamos algumas coisas e não pensamos outras. Então, o que a decolonialidade nos coloca? Uma forma de decolonialidade nos leva a perceber essa leitura crítica ou o processo de ler-se lendo. Nos leva a perceber como nesse processo de colonização que invisibilizou tudo aquilo que herdamos da modernidade, do humanismo e da racionalidade. Nesse mesmo processo, invisibilizamos outras formas de ser e pensar, invisibilizamos outras racionalidades. Lembra que nós falamos da normatividade? Por exemplo, as emoções do nosso corpo não são aleatórias, também tem a sua normatividade, mas nós não levamos as emoções em conta: as nossas intuições, as sensações, aquela coisa de "sinto que é assim, mas não tenho como dizer" desvalorizamos, a ciência não aceita, mas tem a sua lógica.

Eliminamos esse tipo de racionalidade, herdamos essa invisibilização e naturalizamos essa invisibilização. Aceitamos junto com a ciência colonial a invisibilização de outros sujeitos produtores de saber, outras culturas não-europeias, grupos indígenas dentro da nossa própria cultura. Seres não humanos que podem produzir o saber. Nesse momento do desastre planetário que nós estamos vivendo em que a ciência já nos diz que não há a possibilidade de reverter o desastre-podemos minimizar os efeitos e nos preparar para os efeitos, mas não podemos reverter os 
danos ao planeta; há vários estudos que mostram como espécies em extinção reagem ao processo de extinção, ou seja, eles são produtores de conhecimento, mas como não são humanos, nós não os ouvimos. A barata, por exemplo, a tão temida, odiada barata. Como é que a barata sobreviveu tantos milênios? E provavelmente vai ser o único ser que sobreviverá. Em vez de aprender com a barata, o que fazemos? Matamos a coitada. De novo, são outras fontes, plantas e o que existe se olharmos para as comunidades indígenas aqui no Brasil, nós temos essas outras formas de fumar, mastigar, beber plantas que vão permitir o acesso a outras formas de saber. Trata-se de outras formas de saber que as plantas trazem que nós desvalorizamos. A antropologia vai dizer "isso é alucinação, isso é viagem, não sei o quê", mas são formas de saber para essas comunidades. Esses saberes ajudaram essas comunidades a sobreviver. Nós relegamos esses saberes à invisibilidade.

Enfim, sobre a pergunta da Ana Paula: nesse momento, precisamos saber quando a gente considera o foco naquilo que me faz ler e entender o que entendo, naquilo que me faz não entender o que não entendo. Eu preciso levar em conta como a modernidade me levou a não ver outros sujeitos produtores de saberes, a não estar apto ou valorizar outras formas de saber, ignorar toda uma riqueza de valores.

APD: Bem, o Lynn expandiu bastante o escopo da nossa fala (e o vocabulário) e eu vou, então, tentar delimitar novamente. Mas só uma ressalva sobre essa presença forte da abordagem de gêneros textuais, que é uma abordagem discursiva de muitas propostas curriculares, sobretudo para a Língua Portuguesa. De fato foi o Bakhtin que chegou nos currículos, mas o Bakhtin que seria bem interessante é o Bakhtin que fala de refração, sentido refratário do signo, signo não-refratário, a heteroglossia, esse Bakhtin não chegou e também não chegou o Bakhtin (2010) do Marxismo e filosofia da linguagem; chegou essa questão dos gêneros relativamente estáveis que, sim, é uma abordagem discursiva, é o olhar discursivo para a língua, mas acabou, talvez, colocando a criança que está sendo alfabetizada numa posição de sujeito que meramente reconhece e constata um gênero textual que, sim, é colocado como norma e, de certa forma, compromete os usos criativos da linguagem. Isso é problemático - como trata Belintane (2017) - porque a abordagem de gêneros acabou instrumentalizando demasiadamente esses usos "sociais", tornando as crianças menos imaginativas nos usos da linguagem, e mais funcionais ao saberem, por exemplo, reconhecer o que é uma receita, o que é um bilhete etc. Para ele, é um roubo da infância essa "cidadania precoce" que torna o olhar da criança pragmático, instrumental. Acho que "contexto" é uma palavra que o Lynn Mario trouxe que é importante. E, de novo, eu penso que nenhuma proposta pedagógica, mesmo que 
seja partindo de uma abordagem sociocultural e crítica, que é o lócus onde muitos de nós estamos situados, ela também não pode ser colocada como salvacionista. Se é o contexto o meu ponto de partida, se é a prática social o meu ponto de partida, então, que a gente olhe para ele e pense em que medida as pesquisas, as políticas e as práticas voltadas para a linguagem, para o letramento, de certa forma, também não se colocaram naquele lócus de ponto zero. Castro Gomes (2007) falou da húbris do ponto zero que vê a Europa da Modernidade como o lócus de privilégio que arrogantemente se colocou como ponto de partida na produção de saberes. Então, eu tenho me inspirado nisso ultimamente e pensado em que medida a gente também precisa se desfazer de uma certa arrogância e de fazer esse mea culpa, como a decolonialidade nos impele a fazer, de modo a então legitimarmos o pluralismo epistêmico, olhando para essa criança que não está sabendo ler e escrever, e questionar: Em que termos que ela não sabe? O que ela já sabe? O que é colocar ou atestar esse saber letrado dessa criança? Quem é que define isso? Então precisamos aprender com as baratas, Lynn, mas também precisamos aprender com gente, gente que está bem perto da gente, nosso "iguais", que partem do mesmo lócus de enunciação como pré-condição de compreender, desfazer e refazer certas políticas, certas pesquisas, certas práticas. Eu acho que a decolonialidade traz esse olhar crítico.

DF: Quando o Lynn fala sobre a questão do meio ambiente, eu lembro de uma obra da Donna Haraway (2016), Staying with the Trouble: Making kin in the Cbthulucene, em que ela problematiza projetos de filosofia, arte, e o que é considerado não humano. O livro é muito interessante porque ela fala inclusive das aranhas, dos pigeons e como que tudo isso nos ajuda a entender nossa humanidade. É importante isso, porque para a gente que está trabalhando com a questão da heterogeneidade versus homogeneidade/normatividade, fica o convite para pensarmos e sairmos das nossas caixinhas normativas e normatizantes que somos colocados ou colocamos o Outro. E isso é interessante porque precisamos de conhecimentos de filosofia e outros conhecimentos transdisciplinares - aí eu incluo Filosofias da Linguagem e os vários filósofos que aqui foram citados, Bakhtin foi um deles. Assim, vejo a importância do pensamento filosófico, desse questionamento, porque ele também nos leva a nos questionar. Para isso serve este debate: se não ajudar na pesquisa, nos ajuda a pensar nossas famílias, nossas relações sociais. Mas se não for isso, nos ajuda a pensar nossa humanidade, ou a sermos melhores educadores.

LMMS: O Daniel falou agora da importância da Filosofia. Eu sou grande leitor da filosofia, mas eu também vejo problema na Filosofia em se ver. A Filosofia gosta de 
se pensar como o primeiro a pensar tudo. Então, se o filósofo não pensou nisso, é impensável. Eu acho que toda a disciplinarização, toda construção de separabilidade, de uma forma de saber e outra, é problemática. Da mesma forma que a separabilidade de uma língua de outra. Como nós já falamos da normatividade transcendental, a mesma coisa acontece com as áreas de saber. Foucault fala sobre isso com o conceito de disciplina. Não é só uma área de saber, mas também a separação de saberes em disciplinas tem um motivo de controle, de poder que motivam essa "ah, você é de uma área, eu sou de outra". É o problema que sempre tive a minha vida inteira. As pessoas tentam me encaixar numa disciplina.

Então, eu acho que precisamos entender isso no sentido de uma postura ética de fazer um esforço para entender o que não entendemos e sem querer entender tudo. Entender que o não entendimento faz parte do entendimento. Então, evitar esse desejo de olhar para o saber como posse é uma coisa que eu venho trabalhando com professores há 40 anos, eu sempre questionei, eu sempre pergunto "Quem é o aluno nota 10 para você? Aquele que sabe tudo ou aquele que entre o início do semestre e o fim do semestre fez um progresso enorme?" No fim do semestre, pode não ser o 10 daquele que sabe tudo, mas aquele que você daria 10, porque ele sabe tudo, pode não ter aprendido nada. Entender esses tipos diferentes de conceitos de saber, fugindo do conceito totalitário do saber é muito importante. E para chegar na interdisciplinaridade, a gente precisa abrir mão, fugir desses conceitos totalitários do saber e identidades disciplinares. Aqui na USP eu fui professor, estou professor de Literatura e Língua/Linguística, mas, quando eu entrei na USP, fiz concurso para a área de Língua. Sempre me proibiram aqui de dar aula de Literatura, porque eu sou concursado na área de Língua - é assim que as caixinhas funcionam, mas, na pós, felizmente, a gente não tem essas muralhas da China, ou as muralhas da China viraram muralhas pequenas. O muro de Berlim já caiu.

APD: Mais ou menos. Depende do programa (risos)

LMMS: (risos). Depende do programa, mas o nosso, pelo menos. Há linhas de pesquisa em que você pode atuar de forma plural o que, de certa forma, retorna à questão decolonial. Muito interessante e muito importante, porque olhando para os teóricos decoloniais de uma forma geral, o que eles dizem? O que nós aprendemos com as teorias e práticas decoloniais, principalmente as latino-americanas é que primeiro você tem que pensar a partir das margens, pensar a partir daquilo que foi anteriormente invisibilizado, e nós que vamos pensar, a partir daquilo que foi antes invisibilizado, já temos uma história, o nosso pé já está no hegemônico, então a gente vai pensar a partir das margens levando o hegemônico junto e, com isso, não 
exclui o hegemônico, mas entender como o hegemônico está dentro de nós. A tal de mea culpa que estávamos falando, mas mea culpa não no sentido pedir a redenção, não é uma mea culpa salvacionista, uma mea culpa que vai nos levar a perceber como o hegemônico, como a minha cumplicidade com o hegemônico me impediu de ver certas coisas, como a minha cumplicidade com o hegemônico faz com o que eu também seja responsável por essa droga de mundo existente; não é só dos outros, eu também ajudei a produzir. É para eu poder identificar as limitações que isso me impôs e aprender com o não-hegemônico, então, a partir desse andar juntos, pensar com o não-hegemônico e andar junto com o hegemônico também. Quando o não-hegemônico anda junto com o hegemônico, automaticamente o hegemônico vai perder a sua hegemonia, não é? Porque quando o antes invisibilizado sai da invisibilidade aquilo que impôs a invisibilidade para esses elementos já perde o seu poder. Então, introduzindo, trazendo um novo jogador para o campo, a gente muda as regras do jogo totalmente, mas, de baixo para cima.

Portanto, partindo do conceito de leitura crítica, precisamos nos conscientizar que há um não-pensado que as nossas histórias não nos levaram a pensar ainda. Então, tem ainda um grande não-pensado que precisamos pensar. Esse não-pensado porque, por várias razões, porque foi marginalizado, invisibilizado, enfim, não foi pensado, mas precisamos pensar; e tem o impensável, aquilo que não somos, no momento, capazes de pensar, mas que vamos precisar pensar. Eu falei do saber das plantas, por exemplo, e de outras espécies, nós vamos ter que abrir mão do - qual é a palavra que Castro Gomez usa? - do húbris, o nosso húbris humanista de achar que só nós, humanos, temos a capacidade de pensar e, falando da filosofia que o Daniel mencionou, ainda estamos na herança kantiana de que a única coisa que podemos é pensar. O pensamento é finito, porque só podemos pensar através do pensamento. Nós estamos em uma situação planetária onde nós precisamos pensar sem pensar. Deu para entender? Pensar outras formas, porque se a ciência já se esgotou, já nos comprovou que só pensar do jeito que pensamos não é suficiente. Precisamos sentir como a gente vai pensar junto com outras espécies, não pensando porque eles não pensam, não são humanos, não usam a mesma racionalidade; então temos que pensar o incognoscível, o impensável, temos que, em outras palavras, identificar as nossas limitações de pensar.

DF: Lynn, eu concordo plenamente. O que eu quis dizer com o filosofar, não foi a Filosofia disciplinadora, disciplinante, voltar lá para trás e acreditar que a filosofia garante todos os conhecimentos. Referi-me ao filosofar do think through, think further, a provocação da reflexão, à criação do conceito, como colocaram Deleuze e Guattari (2013). Mas é exatamente isso, como é que a gente consegue pensar para além? 
Porque o momento é crítico e pode parecer algo muito distante do professor de línguas estrangeiras, mas é urgente que a gente faça esse exercício filosófico.

APD: E acho até que a expressão "pensamento" decolonial acaba carregando uma contradição na medida em que - alguém diz isso, não é? Acho que o Mignolo? quando não há apenas a legitimidade do pensar, o que está posto pela decolonialidade é, por exemplo, a emergência do corpo, o sentir, e que expande e extrapola para além da razão. Quijano (2007), quando fala da colonialidade do poder - e o Lynn falou dessas dicotomias na universidade, língua e literatura -muitos de nós que lidamos com línguas estrangeiras estivemos historicamente às margens desse currículo e a gente precisa, inclusive, lutar contra uma certa auto-marginalização e repensar a inter-transdiscicplinaridade mais como um mindset e menos como uma prática, porque até então ela não existe, ela não ocorre na prática

Eu tenho trabalhado com três escolas públicas da rede municipal de São Paulo em um projeto do PIBID que olha para contextos escolares multilíngues. Uma das escolas adotou um desenho curricular totalmente inovador, baseado em roteiros de aprendizagem. O diretor, com quem estive há pouco tempo na Faculdade de Educação em uma mesa-redonda e, ao ser perguntado, "Como é que anda o trabalho transdisciplinar, após vocês terem abolido a aula expositiva e o currículo vertical?" ele disse "Olha, ainda não ocorre. A gente ainda não sabe fazer um trabalho transdisciplinar e interdisciplinar". Isso significa não ser possível desenvolver um trabalho transdisciplinar? Não. Acho que se entendida mais como uma mindset, uma visão, uma perspectiva calcada na interlocução entre saberes, a inter/transdisciplinaridade pode ocorrer within and not across, percebe? Por exemplo, em uma aula de inglês que deixa de ser "aula de língua" ao ser repertoriada com que sequer imagina que virá do professor interrupções, indagações, problematizações, que transbordam o linguístico, entende?

DF: Em que medida, então, essa normatividade não tem dois pesos e duas medidas, justamente o que Lynn acabou falando sobre aquelas duas visões de normatividade e qual é a que interessa nesse momento, aquela normatividade que traz uma verdade única ou outra? Outras normatividades, estabelecidas em meio aos movimentos da heterogeneidade?

APD: O que eu tenho pensado nesses movimentos e novas políticas desse governo neoconservador é que essas normatividades que vêm sendo impostas são altamente ideológicas; a normatividade sempre é ideológica, mas, no nosso caso, ela é ideológica e ela também tem um cunho militarista, religioso e positivista, e o que é pernicioso 
nisso é que há um discurso oficial pautado na neutralidade, portanto, "altamente científico" que convence, persuade o senso comum e isso é muito perigoso. Se vocês buscarem as justificativas do movimento pró-homeschooling, por exemplo, o discurso oficial de neutralidade é o seguinte: ao legalizar o bomeschooling no Brasil, garante-se assim o pluralismo pedagógico; isto está posto no site oficial do governo quando, na verdade, a gente sabe que há por trás do bomeschooling, a diversidade sendo entendida como um problema, uma ameaça e, portanto dependendo das escolhas religiosas da família, o bomeschooling permite à família deixar sua criança em casa, "segura", longe da diversidade de modo a tentar endireitar essa criança, sem a "contaminação" da diferença, sobretudo a de gênero, que foi o trigger para esse movimento e o movimento do Escola Sem Partido. Com o programa das escolas cívico-militares é a mesma coisa: um discurso científico, supostamente neutro, muito perigoso e que vem com uma normatividade que convence aquele que não lê nas entrelinhas, um discurso de que as escolas militares têm melhores índices de desempenho - e possuem mesmo, mas não porque são mais seguras e são cívicomilitares, e, sim, porque recebe melhores condições de infraestrutura, de salários, e, claro, são seletivas. Para entrar na escola cívico-militar, o aluno, o adolescente, tem que passar por um processo seletivo. $\mathrm{O}$ bom desempenho desse modelo, como se exalta no discurso do site oficial, esconde, na verdade, a questão da desigualdade social.

DF: E a visão de educação é a própria normatividade...

APD: Exatamente, então essas normatividades são altamente ideológicas e, enfim, a gente precisa ler nas entrelinhas, acho que é por aí.

LMMS: Voltando à preocupação com a Filosofia, o dogmatismo sempre foi uma preocupação da Filosofia- de novo, eu vou voltar ao Kant. O Kant já no século XVIII disse que Filosofia não é só pensar coisas, mas é também - isso é um aspecto da Filosofia - pensar o mundo. E o que a Ana estava apontando agora, por exemplo, aquilo que a tal de neutralidade é um não-dogmatismo, dizer que isso é "a verdade, eu estou falando a mais pura verdade e nada pode me contradizer", isso remete às três coisas que você apontou que são, a religiosidade, a cientificidade e o positivismo, nos quais a neutralidade se esconde. Mas também se falou das filosofias mais atuais, da ideia de construção que nós passamos algumas décadas já no construtivismo e todas as nossas teorias de significação; todas as teorias que usamos nas humanas, na Linguística Aplicada são construtivistas, todas, porque levam em conta o fato de que o processo de construção do significado tem origem em um 
lugar sócio-historicamente construído, então aquilo que nós entendemos é aquilo que aprendemos a entender, que nos ensinaram a aprender. Então, uma das coisas que nos leva à situação, digamos, filosófica, científica e que nós estamos atualmente é justamente um problema filosófico que o construtivismo nos colocou.

Assim, todas as teorias de significação que a gente usa vão nos dizer que é tudo uma questão de interpretação e precisamos levar em conta onde o intérprete está. Quem está falando e quais são os discursos que atravessam esse intérprete, mas levando em conta as questões ontológicas e essas são as teorias que - eles chamam de os Novos Materialismos-, estão pensando o planeta, eles vão dizer "mas o planeta sempre foi visto da perspectiva humana" e a perspectiva humana levou a considerar o planeta como recurso esgotável e está esgotado. O que que nós não conseguimos pensar? Se nós naturalizamos - como de fato fizemos com o construtivismo - nos nossos conceitos de significação, nós eliminamos a possibilidade de entender a natureza sem a presença do ser humano, porque se a significação precisa de um intérprete humano, a natureza com a ausência do ser humano não tem expressão. É isso que nos levou à droga em que nós estamos, usando droga sempre em sentido religioso, para não dizer científico. Não sei se entenderam, precisamos pensar o impensável. O que falta para as nossas filosofias? Faltou pensar como não-humano, então... Ou seja, nós construímos uma situação onde a nossa extinção está, assim, no horizonte, e aí? Como é que podemos pensar de uma forma diferente? Se nós não identificamos as falhas, o dogmatismo que o nosso construtivismo nos colocou, nós não vamos poder pensar de uma forma diferente, nós não vamos aceitar a nossa incapacidade de pensar de forma diferente. Então, precisamos pensar nessa possibilidade que a natureza existe, existiu, - se olharmos nas escalas geológicas existiu por milhões de anos antes do aparecimento do ser humano.

APD: Como sujeito, não como objeto.

LMMS: Exatamente.

DF: Ana, Lynn, muito obrigado por esta conversa tão produtiva e essencial para pensarmos como podemos lidar com a normatividade e a heterogeneidade, conceitos complexos, contextuais e, por isso, extremamente multifacetados.

\section{REFERÊNCIAS}

BAKHTIN, M. (2010). Marxismo e Filosofia da Linguagem. 14. Ed. São Paulo: Hucitec. 
BELINTANE, C. (2017). Da corporalidade lúdica à leitura significativa: subsídios para formação de professores. São Paulo: Scortecci.

BOURDIEU, P. (1997). Outline of a theory of practice. Cambridge: Cambridge University Press.

CASTRO-GOMEZ, S. (2007). Decolonizar la universidad: la hybris del punto cero y el diálogo de saberes. In: CASTRO-GOMEZ, S., GROSFOGUEL R. (ed.) El giro descolonial: Reflexiones para una diversidad epistémica más allá del capitalismo global. Bogotá: Siglo del Hombre Editores; Universidad Central, Instituto de Estudios Sociales Contemporáneos y Pontifi cia Universidad Javeriana, Instituto Pensar.

DELEUZE, G.; GUATARRI, G. (2013). O que éfilosofia? $3^{\text {a }}$ edição. São Paulo: Editora 34.

DUBOC, A. P.; FORTES, O. B. S. (2019). Superdiversity, language, and society: issues on the move. Interview with Jan Blommaert and Massimiliano Spotti (Tilburg University). Educação e Pesquisa, v. 45, pp. 1-21.

FIRTH, A.; WAGNER, J. (1997). On Discourse, Communication, and (Some) Fundamental Concepts in SLA Research. The Modern Language Journal. Vol. 81, issue 3, pp. 285-300.

FREIRE, P. (2014). A pedagogia da tolerância. Rio de Janeiro e São Paulo: Paz e Terra.

GOODWIN, A. L. (2010). Globalization and the preparation of quality teachers: rethinking knowledge domains for teaching. Teaching Education. Vol. 21, No. 1, pp. 19-32.

HARAWAY, D. J. (2016). Staying with the trouble: Making kin in the Chthulucene. Durham and London: Duke University Press.

MENEZES DE SOUZA, L.M.T. (2011). Para uma redefinição de Letramento Crítico: conflito e produção de Significacão. In: Ruberval Franco Maciel e Vanessa de Assis Araujo (Orgs.). Formação de professores de línguas: ampliando perspectivas. Jundiaí: Paco Editorial, pp. 128-140.

QUIJANO, A. (2007). Colonialidad del poder y clasificación social. In: CASTROGOMEZ, S., GROSFOGUEL R. (ed.) El giro descolonial: Reflexiones para una diversidad epistémica más allá del capitalismo global. Bogotá: Siglo del Hombre Editores; Universidad Central, Instituto de Estudios Sociales Contemporáneos y Pontifi cia Universidad Javeriana, Instituto Pensar.

SAVIANI, D. (2013). A pedagogia histórico-crítica, as lutas de classe e a educação escolar. Germinal: Marxismo e Educação em Debate, Salvador, v. 5, n. 2, pp. 25-46. 
SOUSA SANTOS, B. (2007). Para além do Pensamento Abissal: Das linhas globais a uma ecologia de saberes. Revista Crítica de Ciências Sociais, 78, pp. 3-46.

SOUSA SANTOS, B. (2020). A cruel pedagogia do vírus. Coimbra: Almedina.

SOARES, M. (2004). Letramento e alfabetização: as muitas facetas. Revista Brasileira de Educação, n. 25, pp. 5-17. Disponível em: https://www.scielo.br/pdf/rbedu/n25/ n25a01.pdf Acesso em: 20 maio 20.

USP. (2015-2021). Universidade de São Paulo. Projeto Nacional de Letramentos: Linguagem, Cultura, Educação e Tecnologia. Disponível em: http://letramentos. fflch.usp.br/sobre Acesso em: 20 maio 2020.

Recebido: 11/7/2020

Aceito: 5/8/2020

Publicado: 13/10/2020 